\title{
Thermally induced aggregation and its suppression of silkworm small heat shock protein sHSP19.9
}

\author{
Hossain $\mathrm{MT}^{1 \text { \&2*}^{*}}$ and $\mathrm{Y}$ Aso ${ }^{2}$
}

${ }^{1}$ Department of Biochemistry and Molecular Biology, Bangladesh Agricultural University, Mymensingh-2202, Bangladesh. ${ }^{2}$ Institute of Genetic Resources, Faculty of Agriculture, Kyushu University, Fukuoka 812-8581, Japan

\begin{abstract}
About ten genes responsible for small heat-shock proteins (SHSP) have been isolated from silkworm. SHSP19.9 is one of the important member among them. Heat-induced stability of the sHSP was investigated at $60^{\circ} \mathrm{C}$ with $20 \mathrm{mM}$ HEPES buffer $\mathrm{pH} 7.7$ containing $10 \mathrm{mM} \mathrm{NaCl}$ (low-ionic strength). Along with it probable suppression of the aggregation was also examined. At the mentioned reaction medium, SHSP19.9 was observed to be aggregated on the concentration- and time-dependent manners. It was successfully suppressed with dithiothreitol (DTT), higher-ionic strengths, Cysteine residues modifications and molecular chaperone: SHSP20.8.
\end{abstract}

Key words: SHSP19.9, thermal aggregation, silkworm, suppression of aggregation

\begin{abstract}
Bangladesh Animal Husbandry Association. All rights reserved.
\section{Introduction}

When living organisms is exposed to the different environment out of physiological conditions, the cohesive interaction is reduced to disintegrate the protein (Meno, 2003). Namely, tertiary structure of protein is disintegrated by drastic changes in temperatures, a variety of mechanical stresses, extremely acidic or basic $\mathrm{pH}$, pressure extremes, osmotic pressure variations, hypoxia, noxious chemicals etc. These conditions pose a serious threat to the living organism and causing the complete or partial unfolding of cellular proteins that may lead to aggregation and inactivation of protein (Khurana et al., 2001; Torrent et al., 2006; Bellotti et al., 1999).
\end{abstract}

Small heat shock proteins (sHSPs) are a family of ATP-independent molecular chaperones which prevent cellular protein aggregation under cellular stresses by binding to misfolded proteins (Nandini et. al., 2015). sHsps contain a structurally conserved a-crystallin domain of about 100 amino acid residues flanked by varied $\mathrm{N}$ - and $\mathrm{C}$-terminal extensions and usually exist as oligomers which is important for the biological functions of most sHsps (Hilario et al., 2011). Relatively small amount of SHSPs are synthesized constitutively, but these accumulate rapidly during temperature stress. The accumulation of
sHSPs is proportional to the temperature and duration of stress (Waters et al., 1996). The maximum synthesis of SHSP and accumulation were reported to be observed at temperatures just below lethal level (Howarth, 1991). SHSP plays a significant role in stabilization of native conformation, folding, and mediation of correct oligomeric assembly, translocation, and protection from heat denaturation (Morimoto et al., 1994; Ellis \& van der Vies 1991; Wickner et al., 1991; Gething \& Sambrook 1992). Among them, the most important character is the stabilization of protein during heat stress; sHSP stabilizes other nonnative proteins.

Among the ten members of silkworm small heat shock proteins, SHSP19.9 and SHSP20.8 are the two members. These two molecular chaperones suppose to have the aggregation suppressive activity against the aggregation of other nonnative proteins. But in course of preliminary experiment, SHSP19.9 was found to be aggregated at $60^{\circ} \mathrm{C}$ with low-ionic strength (low $\mathrm{NaCl}$ concentration). On the other hand, SHSP20.8 was stable even at autoclave. So, the present study was conducted to observe the thermally induced aggregation of SHSP19.9 at $60^{\circ} \mathrm{C}$ with low-ionic strength and seeking the ways of protection by applying various factors such as Dithiothreitol (DTT), high ionic-strength

*Corresponding author: mthossain@bau.edu.bd 


\section{Thermal aggregation and suppression of sHSP19.9}

(high $\mathrm{NaCl}$ concentration), Cystein residue modified SHSP19.9 and SHSP20.8 as molecular chaperone.

\section{Materials and Methods}

\section{Purification of sHSPs}

Overproduction of SHSPs by E. Coli cells and purification of the overproduced SHSPs were done as described by Hossain et al., (2010). Thus Nterminal His-tagged recombinant SHSPs were prepared. Protein amounts for SHSP19.9 and SHSP20.8 were evaluated using calculated molecular extinction coefficients at $280 \mathrm{~nm}$ of $19940 \mathrm{~cm}^{-1} \mathrm{M}^{-1}$ and $22585 \mathrm{~cm}^{-1} \mathrm{M}^{-1}$ respectively (Pace et al., 1995).

\section{Reagents}

Unless otherwise noted, $20 \mathrm{mM}$ HEPES buffer $\mathrm{pH}$ 7.7 containing $10 \mathrm{mM} \mathrm{NaCl}$ (buffer $\mathrm{C}$ ) was used to prepare all required materials and incubation was done at $60^{\circ} \mathrm{C}$. Aggregation of SHSP19.9 and effects of DTT, high ionic-strength such as $0.1 \mathrm{M}$ HEPES buffer pH 7.7 containing $0.1 \mathrm{M} \mathrm{NaCl}, 50$ $\mathrm{mM}$ Sodium Phosphate buffer $\mathrm{pH} 8.0$ containing $0.1 \mathrm{M} \mathrm{NaCl}$ (buffer $A$ ), Cys residues modified SHSP19.9 and SHSP20.8 on the aggregation of sHSP19.9 was monitored at $60^{\circ} \mathrm{C}$ by spectrophotometer method at $360 \mathrm{~nm}$. All of the used chemicals were prepared freshly. The used concentrations of SHSP19.9 and mentioned factors have been outlined at the legend of the respective figures.

\section{Heat-induced aggregation of sHSP19.9}

Concentration- and time-dependent heat stability of SHSP19.9 was investigated by the spectrophotometer method. Quartz cell $(1.0 \mathrm{~cm}$ width) containing different concentration of sHSP19.9 was incubated in the cell holder for fixed times and the absorbance at $360 \mathrm{~nm}$ was taken continuously by the recordable spectrophotometer (Shimadzu UV-2400). For another case, fixed concentration of SHSP19.9 was incubated for different times in the cell and the absorbance was taken continuously at different wavelengths by the same spectrophotometer (Shimadzu UV-2400). Then the incubated solution was taken from the cell and was centrifuged at $10,955 \times \mathrm{g}$ for $20 \mathrm{~min}$. The resultant supernatant was used to take absorbance at $280 \mathrm{~nm}$ by spectrophotometer (Hitachi GeneSpec III) and compared with control. As SHSP19.9 was aggregated with buffer $\mathrm{C}$, so the higher concentration $(22.8 \mu \mathrm{M})$ of sHSP19.9 was used during 3 hours incubation to observe the time-dependent aggregation based on the change of spectrum. Moreover, for the relatively lower time of incubation (30 minutes) lower concentration of SHSP19.9 $(7.0 \mu \mathrm{M})$ was used. Based on feasibility of the method applied, feasible concentration of sHSP19.9 such as 1.044, 2.5 and $5.0 \mu \mathrm{M}$ were used.

\section{Suppression of SHSP19.9 by various factors}

To observe the suppressive activity of DTT, higher ionic strength and cysteine residue modified sHSP19.9 Shimadzu UV-2400 spectrophotometer at $360 \mathrm{~nm}$ wavelength at $60^{\circ} \mathrm{C}$ was used. Concentration-dependent aggregation suppressive activities were monitored with buffer $\mathrm{C}$.

In presence and absence of fixed $1 \mathrm{mM}$ DTT, the thermal aggregation of SHSP19.9 at various concentration such as 5.0, 3.75, $2.5 \& 1.25 \mu \mathrm{M}$ were monitored. Moreover, Keeping the constant concentration of SHSP19.9 at $2.5 \mu \mathrm{M}$ the activity of DTT was also observed with its various concentration such as $0.5,1.0,1.5,2.0,2.5,5.0$, 7.5 and $10.0 \mathrm{mM}$. On the other hand, higher ionic strength buffer such as buffer $A$ and $0.1 \mathrm{M}$ HEPES buffer $\mathrm{pH} 7.7$ containing $0.1 \mathrm{M} \mathrm{NaCl}$ were used against the various concentration of SHSP such as $5.0,3.75,2.5$ and $1.25 \mu \mathrm{M}$ to monitor the suppression of SHSP19.9 aggregation.

Moreover, cysteine residue modified SHSP19.9 with various concentration such as 5.0, 3.75, 2.5 and $1.25 \mu \mathrm{M}$ were used against the aggregation of same concentration of without modified sHSP19.9 to observe the suppressive activity.

Most sophisticated method named spectrofluorometer (Shimadzu RF-5000) was used to evaluate the chaperone-like activity (CLA) of sHSP20.8 against sHSP19.9 aggregation. It was also attached with thermostatic controlled circulating water bath at $60^{\circ} \mathrm{C}$. Both excitation and emission wavelength were set at $360 \mathrm{~nm}$ with $3 \mathrm{~nm}$ and $1.5 \mathrm{~nm}$ band path respectively. By this procedure both molar concentration ratiodependent CLA of SHSP20.8 against SHSP19.9 aggregation was monitored. To be distinct about 
Hossain and Aso (2017) Bang. J. Anim. Sci. 46 (1):57-64

the performance of SHSP20.8 and the condition of proteins during incubation, the absorbance was monitored at different wavelengths for $2 \mathrm{~h}$ with 30 min intervals.

\section{Results}

\section{Aggregation of SHSP19.9}

SHSP19.9 with low-ionic strength was incubated at $60^{\circ} \mathrm{C}$, and the changes in absorbance at 360 $\mathrm{nm}$ were continuously monitored. As shown in figure 1 , the absorbance increased drastically after a lag-phase for 5 minutes. The increasing rate was clearly dependent on the amounts of sHSP19.9. Using the larger amounts of SHSP19.9, the increased aggregation was observed to be decreased chronologically after 10 minutes of incubation. With the decreased amounts of sHSP19.9 such tendencies were not observed. Spectral change during incubation of SHSP19.9 was also monitored at $60^{\circ} \mathrm{C}$ by spectrophotometer at different wavelengths (Figure 2). Comparing the produced spectra with the spectrum of 0 min incubation, it was found that changes in spectrum happened when the next readings were taken after $30 \mathrm{~min}$ of incubation. Such change in spectrum was observed for every interval up to the last (Figure $2 A$ ). The characteristic changes were observed at $280 \mathrm{~nm}$ and the absorbance at this wavelength was decreased based on the time of incubation.

Figure 1. Concentration-dependent heat-induced changes of sHSP19.9. SHSP19.9 in buffer A demonstrates the changes in absorbance for both panel B and C by spectrophotometer (Shimadzu UV-2400) method

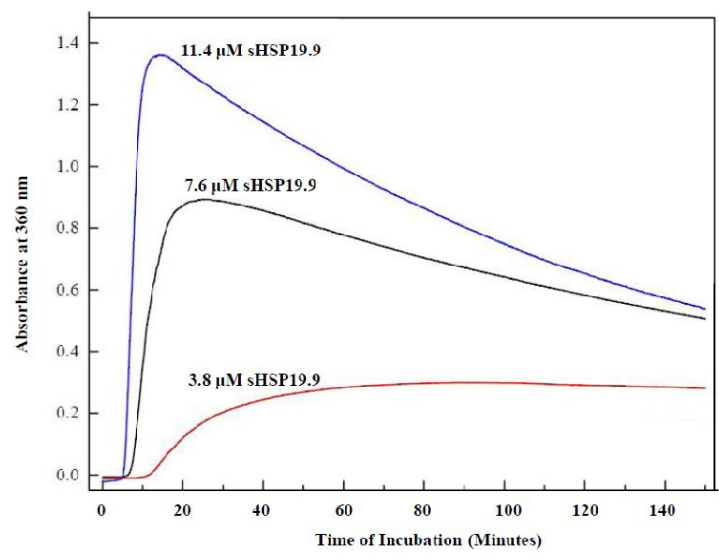

It was happened due to the aggregation of SHSP19.9 as well as loss of polypeptides as after $3 \mathrm{~h}$ of incubation about $15 \%$ sHSP19.9 was observed to be recovered (Figure $2 \mathrm{~B}$ ).

Figure 2. Time-dependent changes in spectrum (aggregation) of sHSP19.9. Panel A demonstrates the continuous monitoring of the changes for $3 \mathrm{~h}$ at 30 min intervals $(\mathrm{a}-\mathrm{g})$ with a fixed $22.8 \mu \mathrm{M}$ sHSP19.9. Panel B represents the changes in spectrum of sHSP19.9 before (a) and after incubation (b) for $3 \mathrm{~h}$ and about $14.9 \%$ SHSP19.9 was observed to be remained in the reaction mixture after incubation

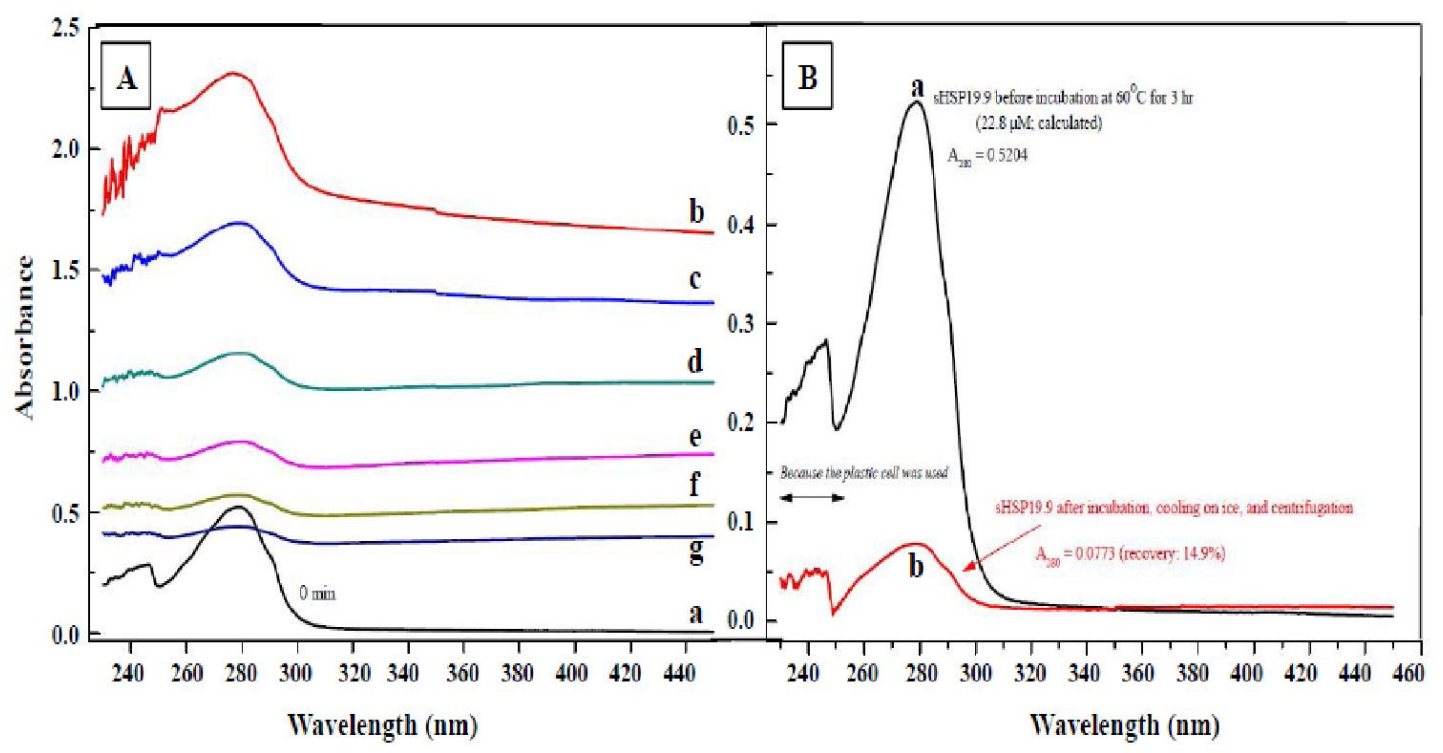


Figure 3. CLA of SHSP20.8 against SHSP19.9 aggregation. Panel A demonstrates the activity for 30 min with a varieties of lower molar concentration ratios; $1: 0$ (a; $7.0 \mu \mathrm{M}$ sHSP19.9 only), 1:0.025 (b), 1:0.05 (c), $1: 0.075(\mathrm{~d})$ and 1:0.1 (e). Panel B shows spectrums of sHSP19.9 $(7.60 \mu \mathrm{M})$ in the presence of sHSP20.8 $(3.67 \mu \mathrm{M})$ at $30 \mathrm{~min}$ of intervals up to $3 \mathrm{~h}$ and inset shows the spectrum of mixture before (a) and after (b) incubation

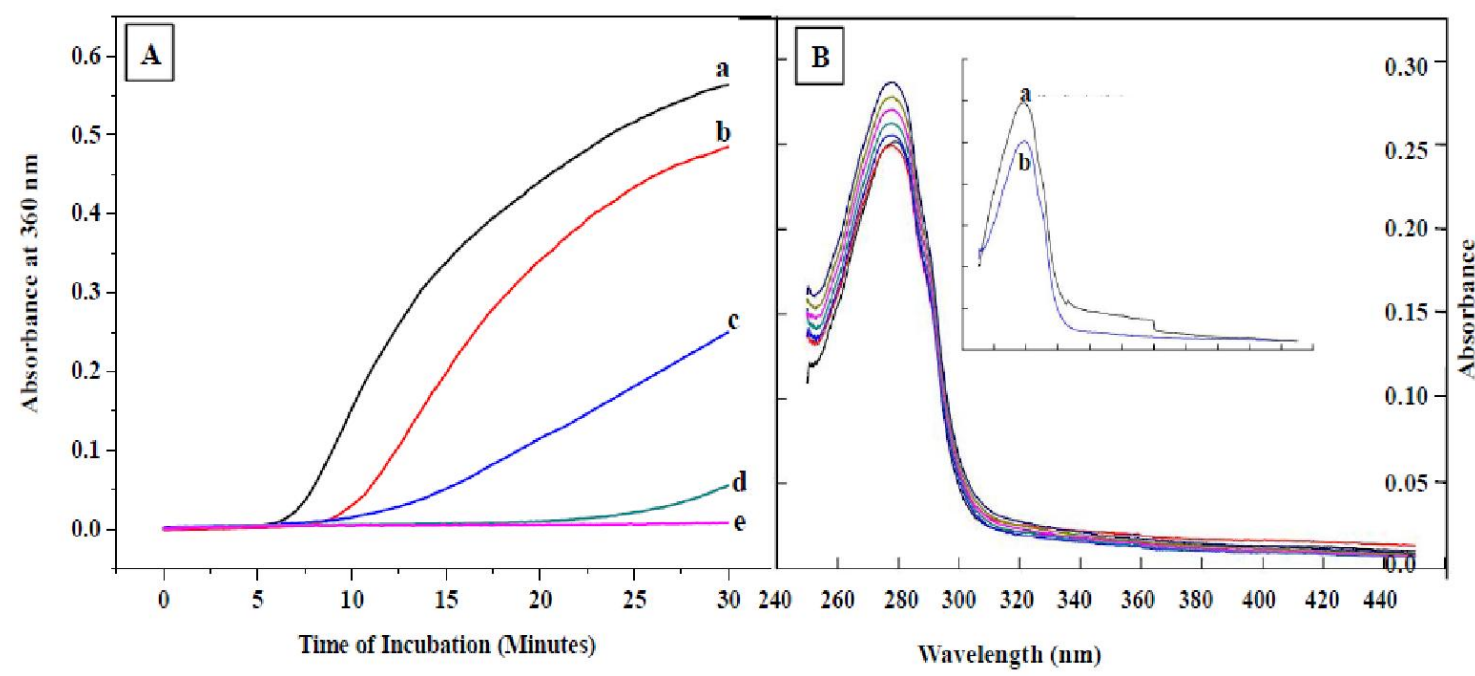

SHSP20.8 against the aggregation of SHSP19.9

SHSP20.8 was used against the aggregation of SHSP19.9 and it was observed that even 1:0.025 molar ratio for SHSP19.9 and SHSP20.8 was effective to suppress the aggregation (Figure 3 ). The activity of SHSP20.8 was concentrationdependent and even 1:0.1 molar ratio for SHSP19.9 and SHSP20.8 was observed to be effective enough to suppress the aggregation completely (Figure 3A).

On the other hand, the performance of SHSP20.8 against sHSP19.9 aggregation was continuously monitored and insignificant differences in spectrum were evident for each interval up to 180 min (Figure 3B). Comparison of spectrum between $0 \mathrm{~min}$ and $180 \mathrm{~min}$ incubation also revealed almost no differences at $360 \mathrm{~nm}$ (Inset figure 3B).

The CLA of sHSP20.8 against sHSP19.9 aggregation was re-examined by spectrofluorometer method and observed the similar potentiality of SHSP20.8 (Figure 4). The aggregation showed by SHSP19.9 in the absence of sHSP20.8 (Figure 4A) was completely suppressed by the entire used molar concentration ratios; $1: 1$ (Figure 4B), $1: 0.4$ (Figure 4C) and 1:0.2 (Figure 4D) for sHSP19.9 and SHSP20.8. These results clearly suggest that SHSP20.8 can suppress the aggregation of sHSP19.9 completely during heat-stress incubation.

Figure 4. Time dependent aggregation of SHSP19.9 by spectrofluorometer at $360 \mathrm{~nm}$ (both excitation and emission) and effect of sHSP20.8. Panel A represents the aggregation of fixed SHSP19.9 (1.044 $\mu \mathrm{M})$ and $B, C$ and $D$ demonstrate the suppression of the aggregation by SHSP20.8 at $1: 1,1: 0.4$ and 1:0.2 molar ratio for SHSP19.9 and SHSP20.8

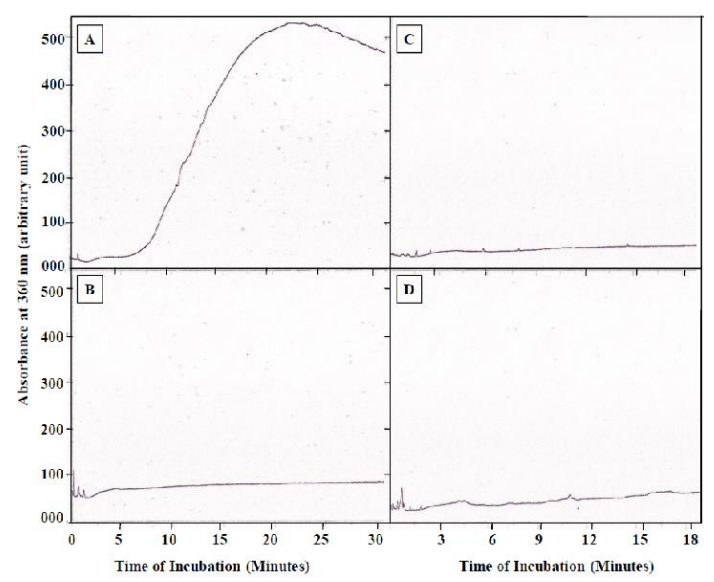




\section{Effects of DTT on sHSP19.9 aggregation}

Different amounts of SHSP19.9 in the presence and the absence of $1 \mathrm{mM}$ DTT were used and observed that DTT can potentially suppress the thermal aggregation of SHSP19.9 (Figure 5A). Using different amounts of DTT against fixed amount $(2.5 \mu \mathrm{M})$ of SHSP19.9, the effects on the suppression of SHSP19.9 aggregation was found to be concentration-independent as all of the used concentration series revealed the similar performances (Figure 5B).

\section{Effects of high ionic-strength on SHSP19.9 aggregation}

To get insight into the effects of high ionicstrength, $0.1 \mathrm{M} \mathrm{NaCl}$ containing $(\mathrm{pH} 7.7) 0.1 \mathrm{M}$ HEPES (Figure $6 \mathrm{~A}$ ) and $0.1 \mathrm{M} \mathrm{NaCl}$ containing $(\mathrm{pH}$ 8.0) $50 \mathrm{mM}$ Sodium Phosphate (Figure 6B) were used. Concentration-dependent aggregation of sHSP19.9 was observed in buffer C, which was completely suppressed with the entire ionicstrength.

\section{Thermostability of Cys residue modified sHSP19.9}

Without Cys residue modification, the SHSP19.9 at low ionic-strength produced increased absorbance on concentration-dependent manner due to aggregation. This property was not evident for the chemically modified SHSP19.9, which can effectively tolerate the stress (Figure7). The Cys residue of sHSP19.9 is capped with mono Iodoacetic Acid during modification and this modified sHSP19.9 do not feel enough affinity to interact with each other for aggregation.

\section{Discussion}

At least ten different genes for SHSPs were found in silkworm larvae and SHSP19.9 is one of the members among them. During incubation, the hydrophobic site of SHSP19.9 as like as other sHSPs exposed and by interaction between these sites of SHSP19.9, its aggregation occurred. Because the structural changes that occur during protein aggregation, protein molecules should also be assembled to form higher order aggregates. The assembly process occurs as a result of the protein-protein pair potential of mean force, which include hard-sphere, electrostatic, van der waals', desolvation, hydrophobic and all other short-range interactions (Chi et al., 2003; Curtis et al., 2002 ). It is widely believed that the partially-unfolded molten globule-like protein structures are especially susceptible to aggregation (Dobson, 2002; Khurana et al., 2001; Plakoutsi et al., 2004; Uversky and Fink, 2004).

Figure 5. Thermal aggregation of SHSP 19.9 at $60^{\circ} \mathrm{C}$ and effect of DTT. Panel A shows the concentration (5.0, $3.75,2.5 \& 1.25 \mu \mathrm{M})$ dependent aggregation in the presence $(e-h)$ and the absence $(a-d)$ of fixed $1 \mathrm{mM}$ DTT and Panel B demonstrates for fixed concentration of SHSP19.9 $(2.5 \mu \mathrm{M})$ in the absence (a) and the presence $0.5,1.0,1.5,2.0,2.5,5.0,7.5$ and $10.0 \mathrm{mM}$ DTT (b-h)

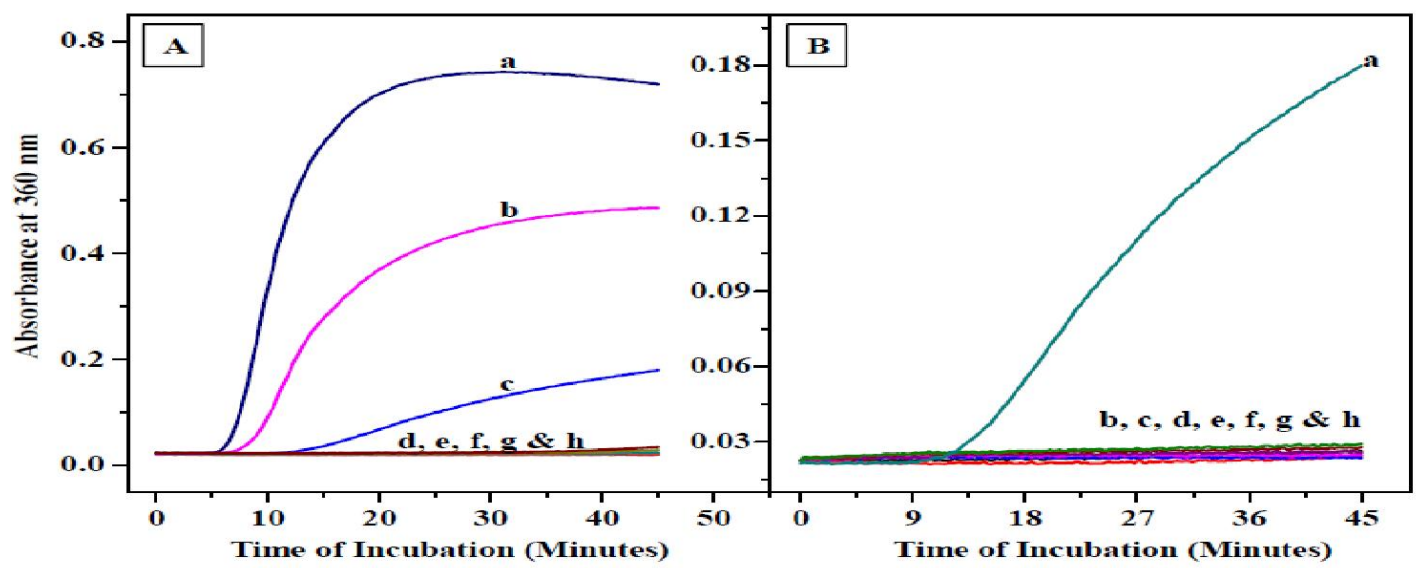


Figure 6. Aggregation of SHSP19.9 in the presence of buffer C (a-d: 5.0, 3.75, 2.5 and $1.25 \mu \mathrm{M}$ ) by spectrophotometer method. Panel A shows the effect of higher ionic-strength buffer, $0.1 \mathrm{M}$ HEPES buffer $\mathrm{pH} 7.7$ containing $0.1 \mathrm{M} \mathrm{NaCl}(\mathrm{e}-\mathrm{h}: 5.0,3.75,2.5$ and $1.25 \mu \mathrm{M})$ and panel B represents the performance of buffer $A(e-h: 5.0,3.75,2.5$ and $1.25 \mu \mathrm{M})$

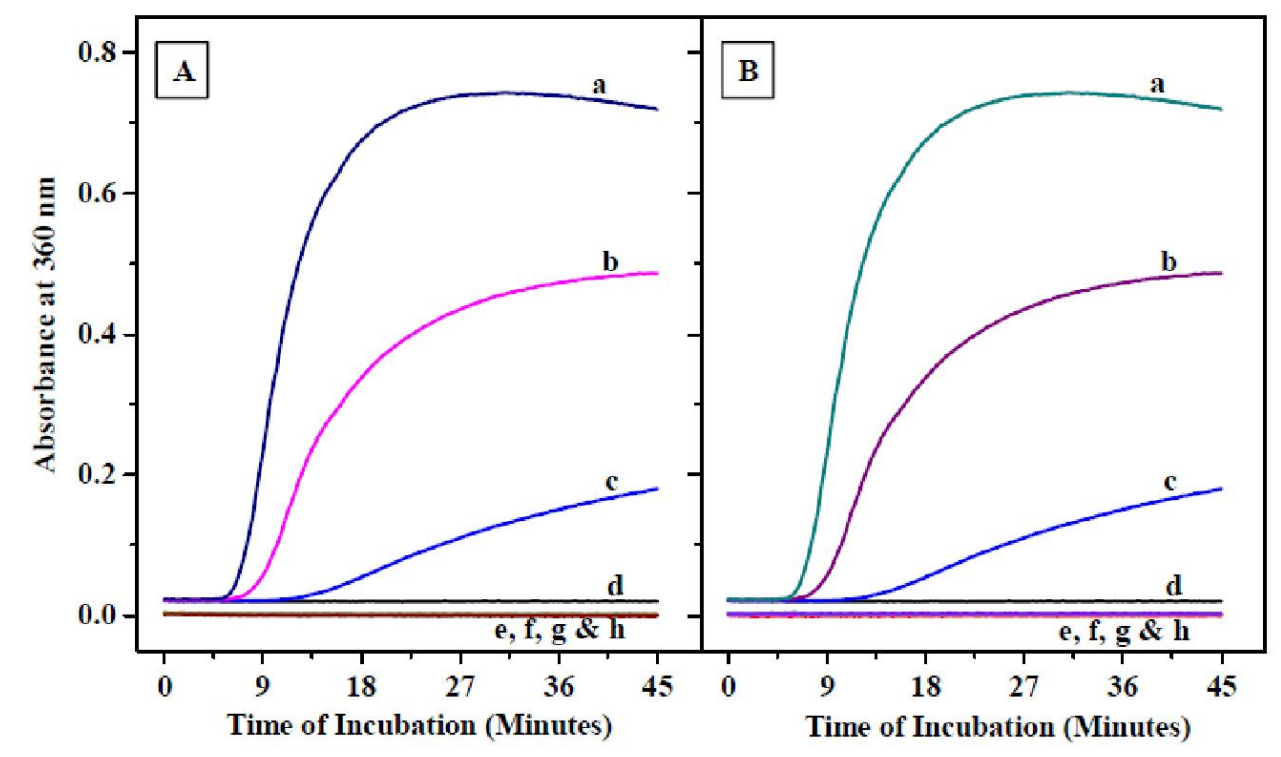

Moreover, from the amino acid sequence of SHSP19.9, it was cleared that SHSP19.9 contained more - $\mathrm{SH}$ (sulfhydryl) residues than -S-S(disulfide) residues (Hossain et al., 2010). So, when sHSP19.9 was incubated with low-ionic strength, the ionic repulsion of the reaction medium is decreased. This condition increased the protein-protein interactions and also interpolypeptide interactions and therefore inter disulfide bonds is produced by the reduced Cys residues and is destabilizing the SHSP19.9 as like as IP-10 (Crow et al., 2001), which was also aggregated due to the presence of reduced sulfhydryl residues.

Among the members of silkworm sHSPs, SHSP20.8 is one of the member, which was used against SHSP19.9 aggregation and observed to be efficient. Molecular chaperones have been shown to bind only aggregation-prone proteins, but not native or already-aggregated proteins (Manna et al., 2001; Wang and Spector, 1994). This rule is also true for SHSP20.8 as it can efficiently stop the further aggregation of SHSP19.9.

DTT is frequently used to reduce the disulfide bonds of proteins as reducing agent and more generally used to prevent intramolecular and intermolecular disulfide bonds from forming between Cys residues of proteins and leading to aggregation of proteins (Bhattacharyya et al., 2003; Sing and Rao, 2002). But fully opposite activity of DTT was observed against SHSP19.9 aggregation. It never accelerated the aggregation but observed to be quite helpful to suppress the aggregation. It happened due to the inhibition of oxidation of Cys residues. Such phenomena also inhibit to form inter polypeptide disulfide bonds and stabilize the SHSP19.9.

Recombinant human interferon-inducible protein10 (IP-10), a 10-kDa C-X-C chemokine with four cysteines, aggregated and this aggregation depended on the presence of reduced sulfhydryl residues on IP-10. The aggregation of IP-10 could be prevented by reduction of its sulfhydryls with dithiothreitol followed by irreversible blockade with iodoacetamide (Crow et al, 2001). Moreover, the chemical modification of carboxyl residues by MIA cause the conformational change of the protein at the tertiary level, so that it conceals hydrophobic residues and reduces the proteinprotein interaction due to loss in hydrophobicity and also reduces the aggregation of protein (Hashemnia et al., 2006) so that chemically modified Cys residue of SHSP19.9 never fell affinity to interact with each other to form the inter polypeptide disulfide bonds. So it was never aggregated at heat stress. 
Harsh environmental conditions or normal physiological extremes lead to situations where cells are subjected to solutions of high osmolality, which causes loss of water, increased crowding, subsequently leading to the aggregation of protein-like macromolecules by increasing intracellular concentrations. But high ionicstrength usually reduces this interaction by keeping the proteins in soluble condition by increasing the water holding capacity of the proteins (Pighin et al., 2008). Such condition also increases the ionic repulsion which decreases the protein-protein as well as the inter polypeptides interaction. Therefore at high ionic-strength the reduced Cys residues of SHSP19.9 do not get enough scope to interact with each other to form inter polypeptide disulfide bonds, which also stabilizes the SHSP19.9 at heat stress.

Figure 7. Thermal aggregation of SHSP19.9 in buffer C. Panel e-h: modified sHSP19.9 (5.0, $3.75,2.5$ and $1.25 \mu \mathrm{M}$ and panel a-d: without modified SHSP19.9 (5.0, 3.75, 2.5 and 1.25 $\mu \mathrm{M})$. Observation was done by spectrophotometer method

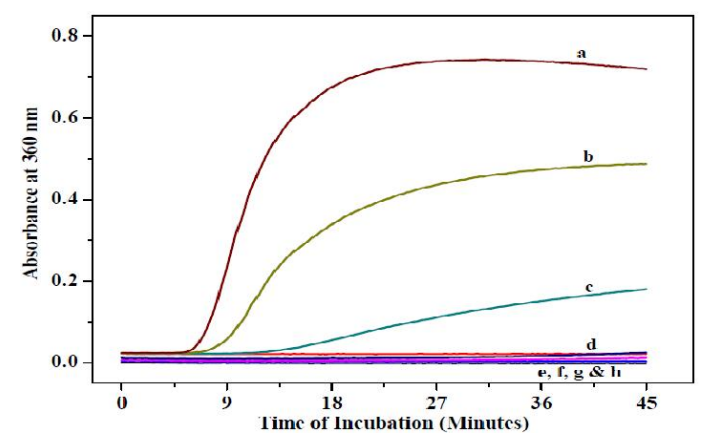

From the above discussion, it is revealed that sHSP19.9 in presence of low ionic condition aggregated on concentration and time-dependent manner, which was not observed when it was incubated with DTT, higher ionic strength HEPES buffer and PBS buffer. Moreover, cysteine residue modified SHSP19.9 can tolerate heat stress at all over the experiment.

\section{Conclusion}

It can be concluded that SHSP19.9 with buffer C was aggregated on concentration- and timedependent manner. But with DTT, high ionicstrength and SHSP20.8, SHSP19.9 can tolerate the heat stress. The chemically-modified sHSP19.9 is also stable at the heat stress. These results clearly messaged that SHSP19.9 failed to show its chaperone like activity at low ionic strength condition like other chaperone. But these findings would be helpful to observe the aggregation suppressive activity of SHSP19.9 against the aggregation of other non-native proteins with the mentioned conditions.

\section{Acknowledgement}

This work was conduct with the approval of the KEK-PF Proposal Review Committee (Proposal No. 2007G665). It was partially supported by the financial aid from the Japan Foundation for Applied Enzymology. It was partially supported by the National Bio-Resources Project (Silkworm) of the Ministry of Education, Culture, Sports, Science and Technology, Japan.

\section{References}

Bellotti V, P Mangione, and M Stoppini (1999). Biological activity and pathological implications of misfolded proteins. Cellular and Molecular Life Science, 55: 977-991.

Bhattacharyya J, P Santhoshkumar and KK Sharma (2003). A peptide sequence YSGVCHTDLHAWHGDWPLPVK[40-60]-in yeast alcohol dehydrogenase prevents the aggregation of denatured substrate proteins. Biochemical and Biophysical Research Communication, 307: 1-7.

Chi EY, S Krishnan, TW Randolph and JF Carpenter (2003). Physical stability of proteins in aqueous solution: mechanism and driving forces in nonnative protein aggregation. Pharmaceutical Research, 20: 1325-1336.

Crow MK, N Karasavvas N and AH Sarris (2001). Protein aggregation mediated by cysteine oxidation during the stacking phase of discontinuous buffer SDS-PAGE. Biotechniques, 30: $311-316$.

Curtis RA, J Ulrich, A Montaser, JM Prausnitz and HW Blanch (2002). Protein-protein interactions in concentrated electrolyte solutions. Biotechnology and Bioengineering, 79: 367-380.

Dobson CM (2002). Getting out of shape. Nature, 418: 729-730.

Ellis RJ and SM van der Vies (1991). Molecular chaperone. Annual Review of Biochemistry, 60: 321-347.

Gething MJ and J Sambrook (1992) Protein folding in the cell. Nature (London), 355: 33-45.

Hashemnia S, AA Moosavi-Movahedi, H Ghourchain, F Ahmad, GH Hakimelehi and AA Saboury (2006). Diminishing of aggregation for bovine liver BLC through acidic residues modification. 


\section{Thermal aggregation and suppression of sHSP19.9}

International Journal of Biology and Macromolecules, 40: 47-53.

Hilario FJ Martin MC Bertolini and L Fan (2011).Crystal structures of Xanthomonas small heat shock protein provide a structural basis for an active molecular chaperone oligomer. Journal of Molecular Biology, 2011 Apr 22;408(1):74-86

Hossain MT, S Teshiba, Y Shigeoka, T Fujisawa, $Y$ Inoko, $D$ Sakano, $\mathrm{K}$ Yamamoto, $\mathrm{Y}$ Banno and $\mathrm{Y}$ Aso (2010). Structural Properties of silkworm small heat-shock proteins: sHSP19.9 and sHSP20.8. Bioscience Biotechnology and Biochemistry, 74 (8): 1556-1563.

Howarth CJ (1991). Molecular responses of plants to an increased incidence of heat shock. Plant cell environment, 14: 831-841.

Khurana R, JR Gillespie, A Talapatra, L Minert, C Ionescu-Zanetti, I Millett and AL Fink (2001). Partially folded intermediates as critical precursors of light chain amyloid fibrils and amorphous aggregates. Biochemistry-US, 40: 3525-3535.

Manna T, T Sarkar, A Poddar, M Roychowdhury, KP Das and B Bhattacharyya (2001). CLA of tubulin. Journal of Biological Chemistry, 276: 39742-39747.

Meno K (2003). Florescence spectroscopy studies on unfolding and disintegration process of dihydrolipoamide dehydrogenase from Bascillus Stearothermophilus. Ph. D. thesis. Faculty of Agriculture. Kyushu University. Japan. pp 109.

Morimoto RI, A Tissieres and C Georgopoulos (eds) (1994). The Biology of Heat shock Proteins and Molecular Chaperones. Cold spring Harbor Laboratory Press, Cold Spring Harbor, NewYork.

Nandini M, K Ramakrishna and K Suguna (2015). Characterization of rice small heat shock proteins targeted to different cellular organelles. Cell Stress Chaperones, 20(3): 451-460.
Pace CN, F Vajdos, L Fee, G Grimsley and T Gray (1995). How to measure and predict the molar absorption coefficient of a protein. Protein Science, 4: 2411-2423.

Pighin DG, AM Sancho and CB Gonzalez (2008). Effect of salt addition on the thermal behavior of proteins of bovine meat from Argentina. Meat Science, $79:$ 549-556

Plakoutsi G, N Taddei, M Stefani and F Chiti (2004). Aggregation of the acylphosphatase from Sulfolobus solfataricus: the folded and partially unfolded can both be precursors for amyloid formation. Journal of Biological Chemistry, 279: 14111-14119.

Singh R and CM Rao (2002). CLA and surface hydrophobicity of 705 ribosome. FEBS Letters, 527: 234-238.

Torrent J, MT Alvarez-Martinez, JP Liautard and R Lange (2006). Modulation of prion protein structure by pressure and temperature. Biochemica et Biophysica Acta, 1764: 546-551.

Uversky VN and AL Fink (2004). Conformational constraints for amyloid fibrillation: the importance of being unfolded Biochemica et Biophysica Acta, 1698: 131-153.

Wang K and A Spector (1994). The chaperone activity of bovine alpha crystalline. Interaction with other lens crystallins in native and denatured states. Journal of Biological Chemistry, 269:1 3601-13608.

Waters ER, GJ Lee and E Vierling (1996). Evolution, structure and function of small heat shock proteins in plants. Journal of Experimental Botany, 47: 325-338.

Wickner W, AJM Driessen and FU Hartl (1991). The enzymology of protein translocation across the Escherichia coli plasma membrane. Annual Review of Biochemistry, 60: 101-124. 